\title{
The needs of health promoters on a health promotion programme for families with adolescents orphaned by HIV and AIDS
}

\author{
Authors: \\ Maseapo P. Mthobeni ${ }^{1}$ \\ Mmapheko D. Peu ${ }^{1}$ \\ Affiliations: \\ ${ }^{1}$ Department of Nursing \\ Science, University of \\ Pretoria, South Africa \\ Correspondence to \\ Maseapo Mthobeni \\ Email: \\ portia.mthobeni@vodamail. \\ co.za \\ Postal address: \\ PO Box 17218, Witbank \\ 1035, South Africa \\ Dates: \\ Received: 15 Oct. 2011 \\ Accepted: 13 Oct. 2012 \\ Published: 01 Feb. 2013 \\ How to cite this article: \\ Mthobeni, M.P. \& Peu, M.D. \\ 2013, 'The needs of health \\ promoters on a health \\ promotion programme for \\ families with adolescents \\ orphaned by HIV and AIDS', \\ Curationis 36(1), Art. \#70, \\ 8 pages. http://dx.doi. \\ org/10.4102/curationis. \\ v36i1.70

\section{Copyright:} \\ (C) 2012. The Authors. \\ Licensee: AOSIS \\ OpenJournals. This work \\ is licensed under the \\ Creative Commons \\ Attribution License.
}

Read online:
The South African communities has shown to have a challenge in accessing health services especially in rural areas; hence the national strategic objective 1.7 aimed at strengthening community systems to expand access to services using the community-based care programmes (NSP 2012-2016). The programmes enhance access to health services whilst promoting health and educating the community to improve health knowledge and work towards attaining a healthy living (NSP 2012-2016). However, the health promoters from the rural Hammanskraal region in the North West Province of South Africa often found themselves rendering the health promotion services in their communities with limited resources. This study aimed at exploring and describing the challenges faced by health promoters in implementing health promotion programmes for families with adolescents orphaned by HIV and AIDS. The study followed a qualitative design. Data was collected using focus group interviews. Participants were purposely selected by the social worker and the health promotion coordinator working at Hammanskraal. The process of data analysis was adapted from the eight steps of Tesch method of data analysis where categories, sub-categories and themes were isolated. The following categories emerged as the needs of health promoters on health promotion programmes for families with adolescents orphaned by HIV and AIDS, (1) financial needs, (2) resources, (3) basic life needs, (4) educational needs and (5) health promoter's needs. It is therefore recommended that equal distribution of resources: including medicine, equipment and finances, should be maintained in order to ensure non-interrupted services.

\section{Introduction}

HIV and AIDS were denoted one of the highest causes of death in South Africa claiming about 314000 people in 2009 (Department of Health 2010:2). The impact of the disease contributed in a growing trend of orphans in South Africa, estimated at 1.95 million AIDS orphans in 2009 (Department of Health 2010:3). Though there is evidence that new HIV infection rate has stabilised for the past 3 years to below 30\%, there is still a greater need for health education and a health promotion programme (NSP 2012-2016:22).

According to Huff \& Kline (2008:5); health education programmes encompasses any planned combination of learning experiences designed to predispose, enable and reinforce voluntary behaviour conducive to health individuals, groups or communities. Even though health promotion emerged from the health education programme, the health promotion programme designates a broader level of outcomes. Whilst the health education programme targets a certain group of individuals living in a specific geographical area; the intervention of health promotion goes beyond the education programme and focuses on the need to establish and sustain a more accessible and equitable distributed system of all poor and underserved groups in a particular community (Huff \& Kline 2008:5).

Therefore, there is a need to achieve different levels of health outcomes from the individuals, families, groups, organisations and communities through a combination of health promotions and health education programmes; hence this study aimed at determining the challenges faced by health promoters in implementing the health promotion programme for families with adolescents orphaned by HIV and AIDS.

\section{Problem statement}

Most adolescents orphaned by HIV and AIDS experience psychological trauma due to parent's illnesses and death; absence of adult guidance and mentoring; unmet needs for love and security; dropping out of school and obtaining social grants (Maqoko \& Dreyer 2007:725). A Health promotion programme seeks to create an awareness of the disease and to prevent the spreading 
of the condition through promoting safe sexual behaviour aimed at protecting the family, partners and the community; establishing support groups; conducting counselling of contact families; giving specific health education related to problems experienced by sufferers (Acutt \& Hatting 2003:275). Sobuce (2007:74) outlined experiences faced by health promoters whilst rendering health promotion as: lack of resources and infrastructures, poor working relations, increased workloads, and economic burden. It is, however, disturbing that the infection rate in the North West Province remained unchanged over a period of 3 years. The infection rate ranged from $30.6 \%$ in $2007,31.0 \%$ in 2008 and $30.0 \%$ in 2009 (Department of Health 2010:31). The health promoters of rural Hammanskraal, were studied to establish the challenges and factors that seemed to constrain the effective health promotion programme from families with adolescents orphaned by HIV and AIDS.

\section{Aims of the study}

This study aimed at exploring the challenges faced by health promoters; therefore describing their needs in a health promotion programme; to isolate possible factors that improved or constrained the effectiveness of health promotion in the families with adolescents orphaned by HIV and AIDS. The results of this study will assist the researcher to determine the needs of health promoters whilst recommending strategies to close any possible gaps towards achieving the effective health promotion strategies.

\section{Trends}

Whilst the numbers of HIV infected individuals increased, access to medical services became difficult to the infected and uninfected individuals in South Africa, especially in the rural areas (NSP 2012:32). When parents fall ill, especially in poor families, children become emotionally affected and the effects of this continue in different ways for the rest of their childhood (Maqoko \& Dreyer 2007:718). Though the epidemic HIV new infection rate seemed to stabilise globally, AIDS-related illnesses remain one of the leading causes of death globally (UNAIDS 2009:8). South Africa contributes to the $71 \%$ of new infection rate in Sub-Saharan Africa (UNAIDS 2009:8). The impact of the HIV new infection rate and the existing infected individuals were mirrored by $46 \%$ of AIDS orphans in 2009 in South Africa (Department of Health 2010:3).

Challenges met by orphaned adolescents ranged from economic hardships; having to leave school; malnutrition and illness; loss of inheritance; fear of isolation; increased abuse and risk of HIV (Maqoko \& Dreyer 2007:719); whilst engaging in early sexual activities in attempts to create their own life story and to redefine themselves (Burns \& Porter 2007:225). Therefore, the health promotion programme should target the activities such as: awareness campaign, lifestyle changes in supportive environment such as families, communities and the health care providers, in this case the health promoters (Acutt \& Hatting 2003:270). The success of a health promotion programme depends on the effective, competent skills of the health promoters.

\section{Research objectives}

The objective of this study was to: 'Explore and describe the challenges met by health promoters in implementing a health promotion programme for families with adolescents orphaned by HIV and AIDS.'

\section{Definition of key concepts}

Health: It is defined by the World Health Organization (1948:100) as 'a state of complete physical, mental and social well-being and not merely absence of disease or infirmity'. The complete state of health was expected from the families with adolescents orphaned by HIV and AIDS.

Health promotion: It is defined by O'Donnel as the science and art of helping people to change their lifestyle and move towards a state of optimal health (Edelman \& Mandle 2002:16). World Health Organization (WHO) views health promotion as 'a unifying concept for those who recognise the need for change in the ways and conditions of living, in order to promote health' (Dennil, King \& Swanepoel 2007:122). In addition health promotion is also defined as the process of enabling people (individuals) to increase control over the determinants of health, and thereby improve it (Dennil et al. 2007:122). In this study the art of helping people to change their lifestyle will be directed to families with adolescents orphaned by HIV and AIDS.

Health promotion programme: It was defined by Huff and Kline (2008:5) as the aggregate of all purposeful activities designed to improve personal and public health through a combination of strategies, including the competent implementation of behavioural change strategies, health education, health protection measures, risk factor detection, health enhancement and health maintenance.

HIV and AIDS: Acquired Immune Deficiency Syndrome (AIDS) is an infectious disease caused by Human Immunodeficiency Virus (HIV) (The free dictionary.com n.d.). The advanced stage of AIDS is fatal, leading to the high mortality rate of adults, specifically in South Africa, hence the increasing number of orphaned adolescents. This study aimed at exploring the perception of health promoters regarding health promotion programmes for families with adolescents orphaned by HIV and AIDS.

\section{Significance of the study}

This study aimed at identifying the challenges encountered by the health promoters in rendering health promotion to the families with adolescents orphaned by HIV and AIDS. This will point out possible factors that improved or constrained the effectiveness of health promotion in the rural Hammanskraal community. Given the results of this study, health planners will be able close any possible gaps regarding the effectiveness of health promotion strategies since health promotion is viewed as the key solution in combating HIV and AIDS. Thus far, the battle against HIV and AIDS is still at large as featured by the infection rate of 1.9 million HIV newly infected in 2008 (UNDAIDS 2009:83). 


\section{Literature review}

Health promotion is seen as the science and art of helping people to change their lifestyle through health promotion and move towards a state of healthy living behaviour that will assist in prevention of diseases including HIV and AIDS (Edelman \& Mandle 2002:16). In addressing this statement, the South African Department of Health invited all the stakeholders, governmental and non-governmental organisations to join hands in the fight against HIV and AIDS by rendering health promotion in the communities (Peu, Van Wyk \& Botha. 2008:15). Whilst the World Health Organisation views health education as a unifying concept for those who recognise the need for change in the ways and conditions of living, in order to promote health (Dennil et al. 2007:122), the art of helping people to change their lifestyle will be directed to families with adolescents orphaned by HIV and AIDS. It is, however, alarming to note the massive increase of HIV and AIDS deaths estimated at 91\% between 1997 and 2006; claiming 350000 lives in 2007, which nearly amounts to 1000 people every day' (UNAIDS update 2009). It is the highest rate when calculated against South Africa's total population. It is, therefore, important to consider research of this nature because it will help close gaps in health promotion services by identifying the areas where health promotion is ineffective or non-existent. This will assist policy makers to come up with better and effective health promotion strategies.

The World Health Organisation (2009) states that the responsibility for health promotion in the health services is shared amongst individuals, community groups, health professionals, health service institutions and government'. Therefore the purpose of health promotion is to raise awareness in a community about its own health status, and to help a community to recognize the existence of its health needs that they may have previously ignored. It is recommended that 'health education should be provided continuously in order to conscientise families with adolescents about their health promotion needs and behaviours' (Peu et al.). Communities, therefore, do need an empowering resource (health promotion) to enable them to attain the state of complete health. This may be done by identifying their own health needs and participating in health enhancing activities and taking responsibility for their health needs.

\section{Research method design Design}

This study was qualitative in nature. The researcher's interest in this design was the interpretive, in-depth approach done in a holistic fashion, through the collection of rich narrative material that is thought to produce more of a subjective science using a flexible research design (Polit \& Beck 2008:763; Burns \& Grooves 2005:24).

\section{Materials}

A focus group interview was the method used to conduct this study. The researcher chose the focus group method for its ability to obtain many viewpoints of different individuals
TABLE 1: Demographic presentation of participants.

\begin{tabular}{llll}
\hline Criterion & Characteristics & $f$ & $\mathbf{\%}$ \\
\hline Health promoters & Caregivers & 6 & 60 \\
& Non-caregivers & 4 & 40 \\
Gender & Female & 6 & 60 \\
& male & 4 & 40 \\
Educational level & High School Education & 8 & 80 \\
& Tertiary education & 2 & 20 \\
Age & $19-29$ years & 8 & 80 \\
& $30-40$ years & 2 & 20 \\
\hline
\end{tabular}

$f$, Frequency.

in a short time (Polit \& Beck 2008:395); in the context of the study participant's work place.

Population consisted of government and non-governmental health promoters, males and females working under the North West Department of Health in rural Hammanskraal, directly and indirectly involved in promoting health care to families with adolescents orphaned by HIV and AIDS. A total of ten participants, four males and six females, ages ranging from 19 years to 38 years, were purposely selected as they met the criteria of the population required. All participants had high school education and two had tertiary education (Table 1). Two people assisted in hand picking the study participants, the health promotion coordinator from the hospital in Hammanskraal, and the social worker working closely with the health promoters involved in the families with adolescents orphaned by HIV and AIDS.

\section{Data collection methods}

Data was collected using the focus group interviews. The study was conducted at the participant's workplace. A briefing session meeting was arranged with the hospital management, the health promotion coordinators and the local hospice centre. The meeting was attended by the representative from both the hospital and the hospice centre and information about the study and the ethical considerations were addressed. An information leaflet with the consent forms for the study participants were issued to the health promotion coordinator and the social worker who assisted in selecting the study participants. Participants were required to bring the signed consent forms on the next meeting as arranged. Two focus group discussions were conducted on different days with the same study participants. The researcher facilitated the interviews as she asked the question: 'What are your needs on a health promotion programme for families with adolescents orphaned by HIV and AIDS'. Using interpersonal skills the researcher probed paraphrased and followed on clues to elicit more information from the study participants. The researcher used a tape recorder to record the interviews and field notes were collected by both the researcher and the senior researcher.

\section{Data analysis}

Data was analysed using the adapted Tesch version as described in De Vos (2005:334) and Cresswell (2003:192). As the researcher collected data using the tape recorder, transcriptions of the interviews were done regularly and accurately, according to the descriptive method. Both the 
researcher and the senior researcher discussed and agreed on the categories, sub-categories and themes to be included in the analysis. Direct quotations were used to support every category and sub-category as themes.

The researcher read through the transcribed information and got a sense of what was said and compiled a list of topics whilst reading through the transcription. The researcher then clustered together similar topics into columns, and arranged them as major- and unique topics. The researcher, using a highlighter, coloured the topics with similar meaning with the same colour, finding the most descriptive word for those topics, turning them into categories. Each category was assembled with the topics similar to the category as sub-categories, and each sub-category with a theme that represented the quote of exact words from the transcription. Both the supervisor and the researcher met and discussed the findings; and reached a consensus about the categories, sub-categories and themes that have been identified. The expertise of the senior researcher acted as the independent coder as she was supervising the entire study.

\section{Ethical considerations}

Ethics is the branch of philosophy that deals with morality (Burns \& Groove 2005:62). This study was conducted for academic purposes; ethical clearance to conduct this study was obtained from the University of Pretoria Research Ethics Committee. Permission was also requested from the North West Department of Health to conduct the study in their province. Regarding participants this study used the following principles to protect them from ethical misconduct: beneficence, respect for human dignity and justice.

\section{Potential benefits and hazards}

The study's intension to explore and describe the needs of the health promoters was aimed at documenting the challenges faced by health promoters to address them and improve the health promotion programme. Participation was completely voluntary. Participants received a full preview of the study stating the purpose, objectives and the research method to be used. The supervisor's involvement was explained in order for them to make an informed decision. Consent was given by participants at home under no duress. Those who chose not to participate they were treated with dignity and respect as well. Participants were also informed of their right to withdraw at any point when feeling emotionally drained.

\section{Recruitment procedure}

The first contact meeting was held at a hospital at Hammanskraal where the researcher introduced the purpose of the study and issued the information leaflet with the consent forms. The health promotion coordinator from the hospital selected the participants according to his knowledge, whilst a social worker from the hospice centre, working closely with the health promoters, handpicked the participants according to her knowledge of their involvement in the families with adolescents orphaned by HIV and AIDS. A total of ten participants, which constituted four males and six females, were purposely selected as they met the criteria of the population required.

\section{Informed consent}

The information leaflet that consisted of the details of the study, the contact numbers and the consent forms were issued to the study participants a week before the interview. They were required to read and sign these at home and bring them with at the next meeting, as arranged.

\section{Data protection}

The data that was collected in the field was captured on audio cassettes and on field notes by the researcher and the senior researcher. These audio cassettes and the field notes were handled and only accessible to the researcher and the senior researcher. Data transcriptions were done soon after each interview and the cassettes were properly labelled and kept safe. The researcher used her field notes and compared these with the data transcription from the audio cassettes. After data analysis, the analysed transcribed documents were forwarded to the senior researcher for confirmation, together with the field notes collected.

\section{Trustworthiness}

Trustworthiness refers to the degree of confidence qualitative researchers have in their data using the criteria of credibility, transferability, dependability and confirmability (Polit \& Beck 2008:196). The strategies applied are outlines (Table 2).

TABLE 2: Strategies to establish trustworthiness.

\begin{tabular}{|c|c|c|}
\hline Strategy & Criteria & Application \\
\hline \multirow[t]{6}{*}{ Credibility } & Prolonged engagement & Focus group discussions were held for $45-60$ min per session with the participants on different days. \\
\hline & Persistent observation & $\begin{array}{l}\text { The tape recorder was used to record all data of interview whilst the researcher collected field notes on the nonverbal and } \\
\text { gestures during the interview. }\end{array}$ \\
\hline & & The same researcher collected data on all occasions to confirm/maintain consistency. \\
\hline & Member checking & The researcher checked constantly with the participants after transcription. \\
\hline & & The results were taken to participants for confirmation post analysis. \\
\hline & Peer debriefing & $\begin{array}{l}\text { The researcher used own peers to discuss issues of concern and the senior researcher was fully supervising the process of } \\
\text { data collection. }\end{array}$ \\
\hline \multirow[t]{2}{*}{ Dependability } & Descriptive data & Data was recorded on tape and transcribed, in addition to the field notes. \\
\hline & & The researcher and the supervisor reached consensus on the findings and results. \\
\hline \multirow[t]{2}{*}{ Confirmability } & Confirmability Audit & The use of field notes, the interview report, and the taped data confirmed the neutrality of the study. \\
\hline & & The presence of the senior researcher to supervise the data collection confirmed the objectivity of the study. \\
\hline \multirow[t]{2}{*}{ Transferability } & Descriptive data & Follow-up visits to collect more data from the participants until no new information was elicited. \\
\hline & Selected sample & The use of purposive sampling to select participants who have knowledge of the topic under study. \\
\hline
\end{tabular}




\section{Discussion of results}

A total of five categories and fourteen sub-categories emerged from the data when analysing the needs of health promoters on a health promotion programme for families with adolescents orphaned by HIV and AIDS. The categories identified were financial needs, resources, basic life needs, educational needs and health promoter's needs (Table 3 ).

\section{Financial needs}

Under the financial needs category: benefits, living wage, and continuous funding, assisted the researcher in understanding the needs of the health promoters on the health promotion programme for families with adolescents orphaned by HIV and AIDS. Participants were made aware that they were volunteers and were only entitled to a stipend: 'We are not asking for too much, but if we could be considered for bonuses or an equivalent acknowledgement to show that we

TABLE 3: Results on the needs of health promoters on a health promotion programme.

\begin{tabular}{|c|c|c|}
\hline Categories & Sub-categories & Themes \\
\hline \multirow[t]{4}{*}{ Financial Needs } & Benefits & Bonuses and incentives \\
\hline & Living Wage & $\begin{array}{l}\text { Monthly salary that will cater for all } \\
\text { their needs }\end{array}$ \\
\hline & & $\begin{array}{l}\text { Yearly increment on stipend } \\
\text { according to interest rate }\end{array}$ \\
\hline & Continuous Funding & $\begin{array}{l}\text { Non-interrupted funding from the } \\
\text { sponsors }\end{array}$ \\
\hline \multirow[t]{8}{*}{ Resources } & Building & Adequate building for patient care \\
\hline & & $\begin{array}{l}\text { Extra consulting rooms to maintain } \\
\text { confidentiality }\end{array}$ \\
\hline & & Hall for extramural activities \\
\hline & & $\begin{array}{l}\text { Mini laboratory to do simple tests } \\
\text { such as CD4 counts }\end{array}$ \\
\hline & & A step-down facility for very ill clients. \\
\hline & Equipments & DVD player for educative videos \\
\hline & & Computers and access to internet \\
\hline & & $\begin{array}{l}\text { - Medical equipments such as } \\
\text { BP machines, thermometers and } \\
\text { glucometers }\end{array}$ \\
\hline \multirow[t]{7}{*}{ Basic life needs } & Food & Food parcels for poor families \\
\hline & & $\begin{array}{l}\text { Lunch for the clients attending the } \\
\text { support group }\end{array}$ \\
\hline & Doctor & $\begin{array}{l}\text { Regular medical screening for health } \\
\text { promoter }\end{array}$ \\
\hline & & $\begin{array}{l}\text { For clients who needs medical } \\
\text { reviews and check-ups }\end{array}$ \\
\hline & & For errands and home visits \\
\hline & Transport & To transport clients to their homes \\
\hline & Debriefing & For mental clearance \\
\hline \multirow[t]{5}{*}{ Educational Needs } & Skill development & Skills and professional training \\
\hline & & Computer training \\
\hline & & In-service training on HIV and AIDS \\
\hline & & Computer training \\
\hline & Health education & $\begin{array}{l}\text { Information educative materials for } \\
\text { the clients }\end{array}$ \\
\hline \multirow{10}{*}{$\begin{array}{l}\text { Health promoter's } \\
\text { Needs }\end{array}$} & Respect & Recognition by management \\
\hline & & Be consulted in decision making \\
\hline & & $\begin{array}{l}\text { Democratic versus authoritative } \\
\text { leadership style }\end{array}$ \\
\hline & Personnel & Add more health promoters \\
\hline & & $\begin{array}{l}\text { Professional nurses to be part of } \\
\text { house visits }\end{array}$ \\
\hline & & $\begin{array}{l}\text { Volunteers during door-to-door } \\
\text { campaign }\end{array}$ \\
\hline & & $\begin{array}{l}\text { An additional administrator for the } \\
\text { hospice }\end{array}$ \\
\hline & & $\begin{array}{l}\text { Employ a security guard to protect us } \\
\text { and our valuables }\end{array}$ \\
\hline & Standardization of & Tea and lunch time extended \\
\hline & & Same services as the governments' \\
\hline
\end{tabular}

are worth something'. Participants required a monthly salary that will cater for all their needs and a yearly increment on the stipend based on the interest rate. The researcher got the impression that the participants were fighting to make ends meet as confirmed by the following: 'We all know that prices have gone up: food, transport and everything else except for our salary. It remains the same, no increment, nothing'. Interrupted funding from sponsors had a huge impact on the participants as they were the ones who suffer most whenever there are no funds: 'We need continuous funding to be able to sustain our programme and maintain ourselves as staff members'.

Medicine SANS Frontier (MSF) reports that adequate salaries and benefits are essential to retaining staff, especially in the health system (MSF 24, May 2007). Similar studies confirmed that a lack of incentives for health workers posed a threat to the health workers' motivation to work (Prasad \& Muraleedharan 2007:21). There are countries like India that employ community health workers on a contract basis, or as regular employment with a fixed monthly salary paid by the government, with required benefits (Prasad \& Muraleedharan 2007:5).

Adequate funding was seen as a challenge by community health workers in the study conducted by Prasad \& Muraleedharan (2007:21). Consequently, there were increased volumes of funding for the fight against HIV and AIDS from developed countries through the Global Fund (Avert n.d.). However, it is vital that sustainability and self-sufficiency in the health sector be encouraged for sub-Saharan African countries to deal with their HIV and AIDS epidemics even if donor funding dries out (Avert n.d.). Thus far it is evident that these funds are making a significant difference, but more money is still needed given the massive scale of the HIV epidemic (Avert n.d).

\section{Resources}

The resources category explored and described buildings and equipment as the sub-categories. Adequate buildings for patient care and a step-down facility will enable the participants to take care of their clients in totality. During the home visits, health promoters came across orphaned adolescents who had to drop out of school to take care of their ill families. Health promoters felt that a hospice facility would admit the ill client and allow these children to study. Quotes such as 'If we could have a place to admit our sick patients, like in families where a parent is ill and children are left to take care of them ...' Working equipment is necessary in order to get the work done. Participants felt marginalised by the limited resources at hand. The BP machines they have are either not working well or not there for others; and the mercury in the thermometers does not respond as required 'The BP machines are either not working well, or the mercury does not go up; it takes time with one patient.'

Failure to secure the ideal building structure was an obstacle to an organisation planning to establish a home-based care facility (Mohapi 2005:9). Privacy and confidentiality during 
consultation and counselling by healthcare providers were some of the possible explanations that led participants to good adherence (Mthembu \& Van Wyk 2010:96). Similar studies revealed that in the preparation for the establishment of a home-based care step-down facility for HIV and AIDS victims, advanced health technology such as X-rays, laboratories, and computers were listed as part of their requirements to run the facility (Mohapi 2005:13).

Step-down facilities provide the in-patient care for patients who no longer require acute intervention (National Department of Health 2006:10). These facilities cater for terminally ill patients requiring palliative care or respite care, and patients may be discharged from hospital into offsite units or they may be referred from their homes by the community health workers (National Department of Health 2006:11). Lack of equipment, furniture, surplus and surplus materials was identified as material obstacles in running the home-based care facility (Mohapi 2005:11). Herman et al. (2009) acknowledged that adequate material support is necessary to enable community health workers to function fully (Hermann et al. 2009).

\section{Basic Life Needs}

The basic life needs category generated two sub-categories that better explained the needs of health promoters, namely, food and transport. There is sporadic availability of nutritional supplements which the participants were not impressed with '... there are families that are so poverty stricken and it does not feel right to leave them in the same situation' ... ' it would relieve much burden on our clients' Transport was mentioned by a lot of health promoters as most of their tasks require transport support. 'Resources such as transport, late orders and delivery of food supplements impact on our service delivery'. Transport is needed to collect and distribute nutritional supplements and educational material, to conduct home visits and attend meetings. Their work revolved around the need for transport.

The research results for the study conducted on orphaned children reveal a $22 \%$ chance of a shortage in basic needs such as food in these families (Heymann \& Kidman 2009:36). According to Cluver, Gardner \& Operario (2009:735) AIDSorphaned children are more likely to report food insecurity and household unemployment. The impact of the AIDS epidemic on South African families has resulted in increased household poverty, food insecurity and unemployment (Cluver et al. 2009:733). The NGO home-based caregivers delivered the much needed material (such as groceries) even though it was regarded insufficient by the community (Orner 2006:239). The South African strategy in poverty alleviation includes programmes such as school feeding schemes, sustainable food and gardening projects, employments initiatives and targeted assistance for grant application (Cluver et al. 2009:736).

The nurses rendering TB treatment and care regard the lack of transport as a major challenge encountered when rendering TB activities at community level (Znavamwe
\& Ehlers 2008:60). In a study by Heymann and Kidman (2009:36) transport was identified as a pitfall as indicated by $22 \%$ of those studied. Related reports revealed that trained field officers visit patients on motorcycles every month to deliver drugs and provide adherence support (API 2009). A study by Mthembu and van Wyk (2010:55) views transport as a contributory factor on adherence.

\section{Educational Needs}

Educational needs were identified with skills development and health education as the sub-categories. The participants wanted support in the form of in-service training and skills development: 'We need to be trained and developed especially in this HIV and AIDS field. "We need our organisation to develop us into professionals'. Informative educational materials are in high demand. The participants prefer to leave the informative educational material with clients when the clients are not prepared to listen to them. They felt that the young people would better recall if they saw and listened to a DVD than being taught verbally

Marquis and Huston (2006:398) reflect that managers have a greater responsibility for seeing that staff is properly trained than they do for meeting educational needs. Williamson (2007:133) believes that providing continuing education opportunities could make an impact on patient care and improve the care that homecare nurses provide. A lack of adequate knowledge regarding HIV and AIDS is evident and the traditional HIV health educational programme has proven to be inefficient in communities in the United States as is shown by an increase in HIV new infection rates (Djokic et al. 2009:25). Likewise Anthony, Williams and Avery (2008:157) in realising the possibility of poor reading comprehension, considered alternative education in the form of videos, pictorials or verbal explanation, and culturally appropriate education by lay health educators.

\section{Health promoters' needs}

Health promoters' needs were identified as: respect, personnel, debriefing and standardisation of services. The need for respect elicited a lot of emotions from the participants: 'We request respect from our management (emotional)'. Recognition by management and the need to be consulted in decision making were mentioned during the interviews: 'We need to be involved in decision making and be consulted in issues involving us'. The participants were of the opinion that they are overloaded with work, and that additional health promoters (personnel) were required to cover the shortage: 'We need more employment of staff to cover the workload and get work done'. In addition the participants felt they were mentally overloaded by the activities and the services they render to the community: '... At times we meet difficult situations in the homes we are visiting and they keep playing back in our minds...'. Also the participants had the feeling that there was duplication of services between them and government health promoters.

Prasad and Muraleedharan (2007:21) noted, in similar studies, managerial issues as part of the challenges faced by 
community health workers. Regarding the discussion on the perception of home healthcare with nurses on empowerment, the participants commented that the organisation should allow nurses to have the ability to sit on committees and have a voice on issues that are meaningful to them (Williamson 2007:146). It was also cited by Mthembu and van Wyk (2010:96) that decision making is an integral part of behavioural change. In response to the increasing HIV epidemic and limited human resources, trained community volunteers have been utilised in HIV-related service delivery at a community level (Tolle 2009:669).

Delobelle et al. (2009:1066) identified that continuous care of HIV and AIDS clients, puts a strain on the caregivers and creates even more stress. Similar studies on debriefing reveal that unresolved stress can lead to decreased productivity, post-traumatic stress disorder, and in some cases even death (Hokanson \& Wirth 2000:255). The purpose of debriefing individuals who experience stressful or traumatic events is to reduce any possibility of psychological harm by allowing people to talk about their experience (Wikipedia2012). Elimination of duplication of activities and enhancing costeffective planning and delivery of services is part of the South Africa's goals and objectives of home-based care (Department of Health 2001:9). Standardisation of services and poor relations between government staff and non-government staff are seen as a threat and weakness to community health workers (Prasad \& Muraleedharan 2007:21-22).

\section{Limitations of the study}

- The study was conducted and limited to the health promoters in a rural area, and the results therefore, cannot be generalised to all health promoters, especially those in urban area.

- Secondly, the sample size used in one province could not be generalised to all health promoters of other provinces. However, health policy makers can make use of these findings to improve the available policies and guidelines regarding home-based care and health promoters.

\section{Recommendations}

Based on the findings of this research, it can therefore be recommended that:

- The integration of the governmental and non-governmental health promotion services should be pursued, in order to prevent duplication of services, therefore ensuring continuity of care. An inter-sectoral collaboration within the different departments is needed to standardise the services.

- Equal distribution of resources: including medicine, equipment and finances should be maintained in order to ensure non-interrupted services.

- The service level agreement made between the government and the non-government organisation on the condition of service for the health promoters need to be clearly defined whilst absorption of all voluntary health promoters into the fulltime workers, according to the conditions of basic employment act, should be the ultimate goal.

\section{Conclusion}

A qualitative study was conducted and followed an exploratory, descriptive and contextual design. The research question, 'what are your needs as health promoters on the health promotion programme for families with adolescents orphaned by HIV and AIDS' pivoted the researcher's focus in this study. Literature control validating the findings was conducted for the 14 identified sub-categories. Health promotion programmes are said to be a pro-active way of empowering the lives of individuals to make healthy choices about their lives. The challenges that the health promoters are faced with in rendering health promotion activities, will delay this whole process.

Multiple challenges have been identified in this study as constraining the rendering of health promotion activities to families with adolescents orphaned by HIV and AIDS. Given the results on the needs of health promoters, health policy makers still have a great challenge of improving resource allocations by equally distributing to all organisations to relieve the currently overloaded health system.

\section{Acknowledgements}

The authors' would like to acknowledge the University of Pretoria, Nursing Department for presenting the learning opportunity for academic development. We acknowledge the Sunrise Hospice Centre and the North West Department of Health for permitting us to conduct the study in their region. To the study participants, this study would not be successfull without their participation.

\section{Competing interests}

The authors declare that they have no financial or personal relationships which may have inappropriately influenced them in writing this paper.

\section{Authors' contributions}

M.D.P. (University of Pretoria) and M.P.M. (University of Pretoria) were responsible for writing this article.M.D.P. made the conceptual contribution of this study. This was one of her post doctoral mentoring project and she supervised the study to its completion. M.P.M. conducted the study under the supervision of M.D.P.

\section{References}

Acutt, J. \& Hatting, S.P., 2003, Occupational Health: Management and Practice for Health Practitioners, 3rd edn., Juta \& Co, Ltd., Lansdowne.

African Press International (API), 2009, Africa: Home-based care as effective as clinical care - home visits help patients save on costly transport to clinic, viewed 14 August 2012, from http://www.africanpress.in.mht

Anthony, M., Williams, J.M. \& Avery, A.M., 2008, 'Health needs of migrant and seasonal farm workers', Journal of Community Health Nursing 25, 153-160. http://dx.doi. org/10.1080/07370010802221768, PMid:18709576

Avert, n.d., HIV and AIDS statistics for South Africa, viewed 27 July 2009, from http:// www .avert.org/safricaststs.htm

Avert, n.d., HIV and AIDS in Africa, viewed 10 August 2010, from http://www.avert. org/HIVand_AIDSinAfrica.htm

Avert, n.d., HIV and AIDS home-based care, viewed 5 August 2010, from http://www. avert.org/aids-hiv-charity 
Burns, N., \& Groove, S.K, 2005, The practice of nursing research, 5th edn., Elsevier, Saunders.

Burns, V.E, \& Porter, E.J, 2007, 'The experience of having become sexually active for teen mothers', Journal of Community health Nursing 24, 4, 215-236. http:// dx.doi.org/10.1080/07370010701645877, PMid: 18092915

Cluver, L., Gardner, F. \& Operario, D., 2009, 'Poverty and psychological health among AIDS-orphaned children in Cape Town, South Africa', AIDS Care 21, 6, 732-741. http://dx.doi.org/10.1080/09540120802511885, PMid: 19806489

Cresswell, J.W., 2003, Research design: Qualitative, quantitative and mixed methods approaches, 2nd edn., Sage, California.

Debriefing-Wikipedia, the free encyclopaedia, viewed 31 August 2012, from http:// en.wikipedia.org/wiki/Debriefing

Delobelle, P., Rawlinson, J.J.L., Ntuli, S., Malatji, I., Decock, R. \& Depoorter, A.M., 2009 'HIV/AIDS knowledge, attitudes, practices and perceptions of rural nurses in South Africa', Journal of Advanced Nursing 65, 5, 1061-1073. http://dx.doi.org/10.1111/ j.1365-2648.2009.04973.x, PMid:19399982

Dennil, K., King, L. \& Swanepoel, T., 2007, Aspects of primary health care: Community health care in Southern Africa, Oxford University Press, Cape Town.

De Vos, A.S., Strydom, H., Fouche, C.B. \& Delport, C.S.L., 2005, Research at grass roots: For the social science and human service professions, 3rd edn., Van Schaik, Pretoria.

Djokic, D., Englund, J., Daum, R., Martin, R., Dozier, T., Potts, S. et al., 2009, 'HIV knowledge and attitudes toward HIV testing of south side Chicago housing authority residents', AIDS PATIENTS CARE and STDs 23, 1, 23-28. http://dx.doi.org/10.1089/apc.2008.0110, PMid:19183078

Edelman, C.L. \& Mandle, C.L., 2002, Health promotion: Throughout life span, 5th edn., Mosby, USA.

Global HIV/AIDS Initiative Network, 2010, Global health and human resources for HIV/ AIDS services in Malawi, Uganda and Zambia, viewed 31 October 2010, from http://www.ghinet.org/downloads/Africa_HRbriefing_final.pdf

Health Promotion Bush Book, viewed 09 June 2009, from http://www.health.nt.gov. au/library/scripts/objectifyMedia. aspx?file=pdf/65/41.pdf\&sitelD=1\&str_ au/library/scripts/objectifyMedia.
title=Bushbook\%20Volume\%201.pdf

Heymann, J. \& Kidmann, R., 2009, 'Psychological and Socio-medical Aspect of HIV/ AIDS', Aids Care 21, 1, 34-42. http://dx.doi.org/10.1080/09540120902927593, PMid:22380977, PMCid:2903780

Hermann, K., Van Damme, W., Pariyo, G.W., Schouten, E., Assefa, Y., Cirera, A. et al., 2009 Community health workers for ART in sub-Saharan Africa: learning from experience capitalizing on new opportunities, Human Resource for Health, 7:31, viewed 14 August 2010, from http://www.human-resources-health.com/content/7/1/31

Hokanson, M. \& Wirth, B., 2000, 'The critical incident stress debriefing process for the Los Angeles County Fire Department: Automatic and effective', International Journal of Emergency Mental Health 2, 4, 249-257. PMid:11217156

Huff, R.M. \& Kline, M.V., 2008, 'Health Promotion in the context of culture', in Sagepubs.com, viewed 04 March 2012, from http://www.sagepubs.com/upm

Maqoko, Z. \& Dreyer, Y., 2007, 'Child-headed households because of the trauma surrounding', HIV/AIDS, HTS 63, 2, 717-731.

Marquis, B.L. \& Huston, J.H., 2006, Leadership roles and management functions in nursing Theory and application, 5th edn., Lippincott Williams \& Wilkins, Philadelphia.
Mohapi, M.E., 2005, Establishment of home-based care (HBC) step-down facility (Hope for life) for HIV/AIDS victims at Pelonomi Hospital in Mangaung Community by 2005, University of Free State, South Africa.

MSF article, 2007, Retaining health workers: The basic, viewed 16 October 2010, from http://www.msf.org

Mthembu, T.G. \& Van Wyk, B., 2010, 'Knowledge, attitudes, beliefs and adherence to antiretroviral therapy among people living with HIV/AIDS receiving treatment at Shongwe Hospital, Mpumalanga Province', Master's Thesis. University of Western Cape.

National Department of Health, 2006, Health facility definitions, Government Printers, Pretoria.

Orner, P., 2006, 'Psychosocial impacts on caregivers of people living with AIDS', AIDS Care 18, 3, 236-240. http://dx.doi.org/10.1080/09540120500456565, PMid:16546784

Peu, M.D., Van Wyk, N.C. \& Botha, A.D.H., 2008, 'Health promotion needs of Hammanskraal families with adolescents orphaned by HIV/AIDS', Health SA Gesondheid 13, 1, 14-28. http://dx.doi.org/10.4102/hsag.v13i1.254

Polit, D.F. \& Beck, C.T., 2008, Nursing research: Generating and assessing evidence for nursing practice, 8th edn., Lippincott, Philadelphia.

Prasad, B.M. \& Muraleedharan, V.R., 2007, 'Community health workers: A review of concepts, practice and policy concerns', UK Government Department of International Development, viewed 15 August 2010, from http://www.crehs.Ishtm.ac.uk/

Sobuce, N.W., 2007, 'The experience of volunteers involved in the Home-Based care of people living with HIV and AIDS', Masters Dissertation, Department of Social Development and Planning, Nelson Mandela Metropolitan University, South Africa.

South Africa, Department of Health, 2001, Policy guideline for youth and adolescent health, Government Printers, Pretoria.

South Africa, Department of Health, 2010, National Antenatal Sentinel HIV and Syphilis Prevalence Survey in South Africa 2009, Government Printers, Pretoria.

South Africa, Department of Health, 2012, National Strategic Plan on HIV, STI's, and TB 2012-2016, Government Printers, Pretoria.

The free dictionary.com, n.d., viewed 09 June 2009, from http://medical-dictionary. thefreedictionary.com/HIV+AIDS)

Tolle, M.A., 2009, 'A package of primary healthcare services for comprehensive familycentred HIV/AIDS care and treatment programs in low-income setting', AIDS Care $14,6,663-672$

Williamson, K.M., 2007, Home healthcare nurses' perceptions of empowerment, Journal of Community Health Nursing 24, 3, 133-153. http://dx.doi.org/10.1080 /07370010701429512, PMid: 17650984

World Health Organization, 2006, World Health Statistics, WHO Publications, Switzerland.

World Health Organization, 2008, Towards universal access: Scaling up priority HIV/ AIDS intervention in the health sector, WHO Publication, Geneva.

World health Organisation, 2009, 'AIDS epidemic update, December 2009', in UNAIDS, viewed 03 October 2011, from http://www.unaids.org

Zvavamwe, S. \& Ehlers, V.J., 2008, 'Implementing a community-based tuberculosis programme in the Omaleke region of Namibia nurses' perceived challenges', Health SA Gesondheid 13(3), 54-68. http://dx.doi.org/10.4102/hsag.v13i3.286 